\title{
A Note on Resource Testing and Temptation
}

\author{
Cagri S. Kumru, John Piggott, and Athanasios C. Thanopoulos
}




\title{
A Note on Resource Testing and Temptation
}

\author{
Cagri S. Kumru \\ The Australian National University \\ John Piggott \\ The University of New South Wales
}

Athanasios C. Thanopoulos

University of Athens

November 2015

\author{
Michigan Retirement Research Center \\ University of Michigan \\ P.O. Box 1248 \\ Ann Arbor, MI 48104 \\ www.mrrc.isr.umich.edu \\ (734) 615-0422
}

\section{Acknowledgements}

The research reported herein was performed pursuant to a grant from the U.S. Social Security Administration (SSA) funded as part of the Retirement Research Consortium through the University of Michigan Retirement Research Center (5 RRC08098401-07). The opinions and conclusions expressed are solely those of the author(s) and do not represent the opinions or policy of SSA or any agency of the Federal Government. Neither the United States Government nor any agency thereof, nor any of their employees, makes any warranty, express or implied, or assumes any legal liability or responsibility for the accuracy, completeness, or usefulness of the contents of this report. Reference herein to any specific commercial product, process or service by trade name, trademark, manufacturer, or otherwise does not necessarily constitute or imply endorsement, recommendation or favoring by the United States Government or any agency thereof.

\section{Regents of the University of Michigan}

Michael J. Behm, Grand Blanc; Mark J. Bernstein, Ann Arbor; Laurence B. Deitch, Bloomfield Hills; Shauna Ryder Diggs, Grosse Pointe; Denise Ilitch, Bingham Farms; Andrea Fischer Newman, Ann Arbor; Andrew C. Richner, Grosse Pointe Park; Katherine E. White, Ann Arbor; Mark S. Schlissel, ex officio 


\title{
A Note on Resource Testing and Temptation
}

\begin{abstract}
This study analyzes the relative performance in terms of welfare of the current US PAYG system compared to an array of cost equivalent alternative specifications of means-tested pension programs. We conduct our analysis under two different settings. While in the first setting, individuals have standard preferences, in the second setting individuals have self-control preferences. We show that the implications of the reform substantially differs across the two settings.
\end{abstract}

\section{Citation}

Kumru, Cagri S., John Piggott, and Athanasios C. Thanopoulos. 2015. “A Note on Resource Testing and Temptation.” Ann Arbor, MI. University of Michigan Retirement Research Center (MRRC) Working Paper, WP 2015-340.

http://www.mrrc.isr.umich.edu/publications/papers/pdf/wp340.pdf 


\section{Introduction}

Many social security systems across the world subject pension benefits to some form of earnings test. Typically, this takes the form of a reduction in accrued pension benefits according to a specific rate ("taper rate") when an individual's earnings exceed a certain threshold. The rules (taper rates, thresholds and type of earnings that are subject to the test) vary significantly across countries and pension schemes. In addition, the underlying pension schemes on which an earnings test may apply are chosen from a wide array of alternative pension systems, ranging from purely "unfunded" (Pay-As-You-Go) to "fully funded."

On several occasions, means testing has appeared as a simple device to provide adequate insurance to lower income households in a budget-neutral way. The idea is that a fiscally neutral reallocation of benefits would target poorer households and ensure an adequate and more equitable post-retirement income, without compromising any of the core properties of insurance provision these programs have for higher income households. Unfortunately, this wouldn't obtain without a cost, especially in the medium / long run: Means-testing is very likely to erode the self-financing potential of the system by discouraging individual savings and undermining work effort. This, in turn, may increase the medium/long - term fiscal cost of means testing and effectively offset one of the main motivations behind means testing, namely, maintaining fiscal neutrality.

Recent empirical and experimental findings in the economics literature have highlighted the important impediments to savings that agents may face when their preferences depart from the standard specification that has been encountered so far in the literature. This calls therefore, for an assessment in a fairly precise and quantifiable manner of the behavioral implications of means-testing retirement benefits. A question of particular interest would involve whether (and the extent to which) the documented in the means-tested literature distortions related to individual savings and labor supply would be further exacerbated (or mitigated) as a function

of the rate by which retirement benefits are "phased out" in an environment where agents have non-standard preferences.

In this paper, we explore quantitatively the welfare consequences of introducing means testing of pensions as an alternative to an earnings dependent and progressive "unfunded" (Pay-As-You-Go) program when the population has self-control preferences. To this end, we use a general equilibrium OLG model with labor-leisure choice, uninsurable individual income shocks, borrowing constraints and missing annuity markets, and calibrate our economy to that of the US. We conduct our analysis in two stages involving two economies that only differ in agents' preference specifications, but are otherwise identical. We conduct our analysis in a partial equilibrium framework in order to control for the general equilibrium feedback effects. Our ultimate goal is to assess from a welfare standpoint the scope of the introduction of means-testing to an earnings dependent and progressive "unfunded" (Pay-As-You-Go) scheme, without altering the expected present value cost (EPVC) of the latter. We restrict our analysis to PAYG systems since the different logic and mechanics of "unfunded" versus "funded" systems eventually induce entirely different risk-sharing properties as well as savings incentives. 
Therefore, their welfare implications already diverge significantly just because of this difference, without taking into account any means-testing policy. ${ }^{1}$

The implications of various social security arrangements under different modelling assumptions are well analyzed in the literature. ${ }^{2}$ Several studies [e.g. Storesletten et al. (1999)] comparing different social security systems typically compare welfare across alternative steady states, each corresponding to a stationary equilibrium with a different social security system. Focusing only on unfunded social security, Imrohoroglu et al. (1995) emphasize the detrimental effects that such an arrangement has to the overall welfare in a country. However, all the above studies ignore alternative preference specifications that may be binding in several cases: Imrohoroglu et al. (2003) and Fehr et al. (2008) use time-inconsistent preferences while Kumru \& Thanopoulos (2008) use self-control preferences to highlight that in a context of unfunded social security welfare may be critically affected by the preference specification. ${ }^{3}$ Kumru \& Thanopoulos (2011) analyze the welfare and aggregate implications of an array of social security arrangements in two different economies. In the first economy, all individuals have standard preferences in which social security arrangements provide insurance against longevity and income fluctuations but distort savings and labor supply decisions. In the second economy, individuals have self-control preferences and hence, the primary function of social security as a forced savings mechanisms comes up with an additional benefit: reducing temptation. They show that the welfare rankings of the programs significantly differ in two different economies. In the current study we extend Kumru \& Thanopoulos (2011) and analyze the welfare and aggregate implications of a set of means-tested pension programs as an alternative to the current PAYG program.

Although social insurance benefits have been means-tested for a long time, these policies have only recently attracted systematic attention from economists. By using a partial equilibrium model with a binary labor-leisure choice Sefton et al. (2008) and Sefton \& van de Ven (2009) analyzed the welfare implications of the means-testing of pension benefits and the interactions between various tax schemes and means-tested benefits respectively. Kumru \& Piggott (2009) extend Sefton et al. (2008)'s model to analyze the implications of means-tested benefits in a general equilibrium framework. Both studies report that means-testing increases welfare. Golosov \& Tsyvinski (2006) analyze the implications of asset (means) testing disability insurance and find significant welfare gains from asset testing. In a recent paper, Kitao (2014) analyzes various social security reform proposals including means-testing of benefits and shows that although means-testing can serve as a useful tool from a budget balancing standpoint, it yields the worst labor disincentives especially among the elderly. In contrast, Cremer, Lozachmeur \& Pestieau (2008) show analytically that the empirical studies showing that an

\footnotetext{
${ }^{1}$ See, e.g., Kumru \& Thanopoulos (2011) for a comparative analysis of unfunded versus funded systems using self-control preferences.

${ }^{2}$ The interest in the welfare implications of a social security system has been sparked with the seminal work of Diamond (1965). Earlier quantitative models that assessed the welfare implications of the system were developed by Feldstein (1985) and Auerbach \& Kotlikoff (1987).

${ }^{3}$ For a detailed introduction to the mechanics of the hyperbolic consumption model and dynamically inconsistent preferences see Angeletos et al. (2001).
} 
earnings test has an adverse effect on labor supply are not sufficient evidence to advocate their suppression, since the earnings test may be part of an optimal system for agents with low values in the parameter they model heterogeneity, i.e., productivity and disutility of labor (health status). Despite the fact that literature focusing on analyzing the implications of the means-tested pension programs is growing, it is still unknown whether and to what extent welfare and aggregate implications of means-tested pension programs are sensitive to individuals' self-control problems and this is the area our paper aims to contribute.

In order to capture our agents' temptation towards current consumption, our model economies make use of the preference structure pioneered by Strotz (1956) and Phelps \& Pollak (1968) and further elaborated by Gul \& Pesendorfer (2004) to model self-control issues. Gul \& Pesendorfer (2004) identified a particular class of utility functions that provide a time-consistent model suitable for addressing the preference reversals that motivated the time inconsistency literature. The key theme here is that self-control preferences assume that agents maximize a utility function that is a 'compromise' between the standard utility (or 'commitment' utility) and a 'temptation' utility. The conflicting ways by which agents derive utility in this setting, is the device through which the trade-off between the temptation to consume on the one hand, and the long-run self interest of the agent on the other is captured. The main benefit is that self-control preferences remain perfectly time-consistent and, contrary to time-inconsistent preferences, allow agents in our model to commit. With the exception of the aforementioned difference in the specification of preferences, our model specification follows that of Huggett \& Parra (2010).

Our paper's contribution to the literature is two-fold. First, it enhances the scope of studies on means-testing by taking self-control issues into consideration. This allows us to analyze the possible interaction between means-testing and self-control issues, and to explore the possibility to identify separately the disincentives to savings that are due to either of those. Second, in contrast to earlier studies on means-testing, our paper compares means-tested programs in two different settings. In the first setting, we keep the expected present value cost of the all programs including the PAYG program constant. This allows us to isolate the implications of the phase-out rate. Later, we also look at the implications of the means-testing, varying the benefit rate while keeping the minimum guaranteed benefit fixed i.e. varying the EPVC.

Our results show that individuals' self-control problems would have a role in determining the welfare ranking of the programs. When the cost of the system fixed, lower taper rates do not generate additional tax distortions. When individuals have standard preferences, $80 \%$ taper rate generates the highest welfare among the means-tested programs. This is because $80 \%$ taper rates improves the distribution of income and hence, generates higher welfare. Interestingly, when individuals have self-control preferences, $0 \%$ taper rate generates the highest welfare among means-tested programs. When individuals have self-control preferences, they would like to avoid high temptation. Higher taper rates enlarge the choice sets of certain individuals and increase their self-control costs. On other hand, $0 \%$ taper rate provides a lower amount of benefits to all individuals without increasing certain individuals' self-control costs. In other 
words, when individuals have self-control preferences, $0 \%$ taper rate's self-control cost reducing benefit exceeds higher taper rates' redistributional benefits.

When the cost of the program is varied, lower taper rates come up with huge tax distortions and hence, in both cases, means-tested programs with $100 \%$ taper rates maximizes the welfare. In this case, it is important to note that, all means-tested programs generate higher welfare benefits than the PAYG pension program. When individuals have self-control references, higher taper rates generate larger welfare gain. Since the cost of the system varies, even individuals with self-control preferences prefer the system with low tax distortions.

The rest of the paper is organized as follows: In sections 2 and 3, we present the model economy and the calibration process, respectively. Section 4 presents the results and Section 5 concludes. The details of numerical analysis and the remaining figures are reported in the Appendix.

\section{The Model Economy}

We use a general equilibrium OLG model economy with uninsured idiosyncratic shocks to labor productivity and mortality.

\subsection{Demographics and Endowments}

Time is discrete. The economy is populated by overlapping generations of individuals. Each period $t$ a new generation is born. ${ }^{4}$ Let $j \in \hat{J}=\left\{1,2, \ldots, j^{*}, \ldots J\right\}$ denote age. Individuals live a maximum of $J$ periods and retire at an exogenously determined retirement age $j^{*}$ and receive relevant pension benefits. The population grows at a constant rate $n$. An individual's probability of surviving up to age $j$ conditional on surviving up to age $j-1$, is denoted by $s_{j}$. Demographic patterns are stable and the constant cohort share of the generation $j$ can be written as follows:

$$
\mu_{j}=\frac{s_{j} \mu_{j-1}}{1+n} \text { for } j=2,3, \ldots, J
$$

where $\sum_{j=1}^{J} \mu_{j}=1$.

An agent's labor productivity in period $j$ (equivalently at age $j$ ) is given by a function $\omega\left(e_{j}, j\right)$ mapping the period shock $e_{j}$ and the individual's age $j$ into labor productivity - effective units of labor unit per unit of time worked.

\footnotetext{
${ }^{4}$ Because we are only interested in steady state values, time subscripts will be dropped from the equations during the rest of the analysis.
} 


\subsection{Preferences}

We consider two distinct economies. In the first economy, individuals have preferences over consumption and leisure sequence $\left\{c_{j},\left(1-l_{j}\right)\right\}_{j=1}^{J}$ represented by a standard time separable utility function. In the second economy, individuals have recursive self-control preferences. Let $V(x)$ denote the maximized value of the expected discounted objective function with state $x$. The utility function of an agent with standard preferences is as follows:

$$
V(x)=\max _{c, l} u(c, 1-l)+\beta E V\left(x^{\prime}\right),
$$

where $E$ is the expectation operator, $\beta$ is the time-discount factor, and $x^{\prime}$ denotes next period state variable. Expectations are taken over the stochastic processes that govern idiosyncratic labor productivity risk and longevity.

In the second economy, agents feature self-control preferences. That is, their preferences are such that in every period they induce a temptation to consume their entire wealth. Resisting temptation gives rise to a self-control cost; note that the latter feature is absent in models with CRRA and quasi-hyperbolic preferences. We follow Gul \& Pesendorfer (2004) and DeJong \& Ripoll (2007) and proceed to model self-control preferences recursively.

Let $V(x)$ denote the maximized value of the expected discounted objective function with state $x$. The utility function of an agent is as follows:

$$
V(x)=\max _{c, l}\left\{u(c, 1-l)+v(c)+\beta E W\left(x^{\prime}\right)\right\}-\max _{\check{c}} v(\check{c})
$$

where $E$ is the expectation operator; $u($.$) and v($.$) are momentary utility and temptation$ functions, respectively; $c$ represents the "commitment" consumption; and $\check{c}$ is the "temptation" consumption. In particular, $v(c)-\max _{\check{c}} v(\check{c})$ denotes the disutility from choosing consumption $c$ instead of $\check{c}$.

\subsection{The Public Sector}

We model tax and transfer functions following Huggett \& Parra (2010). They capture the features of the US social security and federal income taxation. The tax function $T_{j}$ is the sum

of social security $\left(T_{j}^{s}\right)$ and federal income $\left(T_{j}^{i n c}\right)$ tax functions. Let $x_{j}^{1}, x_{j}^{2}$, and $y_{j}$ stand for an individual's average earnings up to period $j$, asset holdings, and labor income respectively. Notice that $y_{j}=w \omega\left(e_{j}, j\right) l_{j}$.

$$
T_{j}\left(x_{j}^{1}, x_{j}^{2}, y_{j}\right)=T_{j}^{s}\left(x_{j}^{1}, y_{j}\right)+T_{j}^{i n c}\left(x_{j}^{1}, x_{j}^{2}, y_{j}\right)
$$

\subsubsection{Income Taxes}

We determine income taxes in the model economy by applying an income taxation to an individual's income. More specifically, we choose income taxes $T_{j}^{i n c}\left(x_{j}^{1}, x_{j}^{2}, y_{j}\right)$ before and after 
the retirement age $j^{*}$ that successfully mimic the average effective tax rates for two types of households: head of household is 65 or older, and head of household is younger than 65 . When generating the tax function we follow the steps in Huggett \& Parra (2010). First, we use a quadratic function passing through the origin that minimizes the squared deviations of the tax function from data to approximate the 2001 income tax data. Second, we express our model in 2001 dollars. Third, the average tax rates on model income is calculated by using the estimated tax function. Model income is the sum of labor income $y_{j}$, asset income $x_{j}^{2}$, and pension benefits.

Since individuals face stochastic life-span, and private annuity markets are closed by assumption, a fraction of the population will leave accidental bequests. The government confiscates all accidental bequests and delivers them to the remaining population in a lump-sum manner. We denote these transfers by $\eta_{t}$. Finally, the government faces a sequence of exogenously given consumption expenditures $\left\{G_{t}\right\}_{t=1}^{\infty}$. This consumption will be financed through income taxes and taxes on consumption $\left(\tau_{c}\right)$.

\subsubsection{Pensions}

In the benchmark case, the social security mimics the US earnings-dependent PAYG social security. More precisely, the model social security system taxes an individual's labor income and makes pension payments after retirement. Taxes are proportional to labor earnings for earnings up to maximum taxable level $y_{\max }$. The social security tax rate is denoted by $\tau_{s}$. Starting with retirement age $j^{*}$, an individual receives pension benefits $b\left(x^{1}\right)$ which is a fixed function of equally weighted average earnings $x^{1}$ up to age $j^{*}$. The earnings that enter into the calculation of of $x^{1}$ are capped at the maximum $y_{\max }$. After the retirement $x^{1}$ remains constant at its value at retirement.

$$
\begin{gathered}
x_{j+1}^{1}=\left[\min \left\{y_{j}, y_{\max }\right\}+(j-1) x_{j}^{1}\right] / j \\
T_{j}^{s}\left(x_{j}^{1}, y_{j}\right)=\left\{\begin{array}{c}
\tau_{s} \min \left\{y_{j}, y_{\max }\right\}: j<j^{*} \\
-b\left(x^{1}\right): j \geq j^{*}
\end{array}\right.
\end{gathered}
$$

The relationship between average past earnings $x^{1}$ and social security benefits $b\left(x^{1}\right)$ mimics that of the US. As in the US system, benefits are a piecewise-linear function of average past earnings. ${ }^{5}$ We set the bend points and the maximum earnings equal to the actual values used in the US social security system, i.e., the first, second, and third segments of the benefit function have slopes equal to $0.90,0.32$, and 0.15 respectively. The bend points occur at 0.21 and 1.29

\footnotetext{
${ }^{5}$ After normalizing the average past earnings and benefits to measure them as multiples of the average earnings in the US, the US social security system benefits have the following structure: the first, second, and third segments of the benefit function have slopes equal to $0.90,0.32$, and 0.15 respectively. The bend points occur at 0.21 and 1.29 times average earnings and the maximum earnings that enter into the benefit calculation are equal to 2.42 times the average earnings. These normalized values are calculated by Huggett \& Parra (2010) using the data provied in the Social Security Handbook (2003).
} 
times average earnings and the maximum earnings that enter into the benefit calculation are equal to 2.42 times the average earnings.

Subsequently, we replace the earnings-related PAYG with a means-tested pension program. In the means-tested program, retirees' benefits are determined through income and asset tests. If income and asset levels are lower than the threshold levels, retirees receive the full penison $\left(b^{\max }\right)$, otherwise their benefits are reduced by the benefit reduction (taper) rate, $\phi \in[0,1]$. The means-tested pension program is financed through a flat tax on working age individual's income.

$$
T_{j}^{s}\left(x_{j}^{1}, y_{j}\right)=\left\{\begin{array}{c}
\tau_{s}\left(y_{j}+x_{j}^{2}\right): j<j^{*} \\
-b_{j}^{*}\left(x_{j}^{2}\right): j \geq j^{*}
\end{array}\right.
$$

where

$$
b_{j}^{*}\left(x_{j}^{2}\right)=\max \left\{b_{j}^{\max }-\phi\left(x_{j}^{2}\right), 0\right\} .
$$

\subsection{An Individual's Decision Problem}

Hence, the agent's growth-adjusted budget constraint can be written as

$$
\left\{\begin{array}{c}
c_{j}+(1+g) \frac{x_{j+1}^{2}}{r} \leq(1+r) \frac{x_{j}^{2}}{r}+y_{j}-T_{j}\left(x_{j}^{1}, x_{j}^{2}, y_{j}\right) \text { when } j<J, \\
c_{J}=(1+r) \frac{x_{j}^{2}}{r}-T_{j}\left(x_{j}^{1}, x_{j}^{2}, y_{j}\right) \text { when } j=J .
\end{array}\right\}
$$

We further assume that agents cannot borrow against their future income at any age:

$$
x_{j}^{2} \geqslant 0, \forall j
$$

An individual's decision problem in our model economy can be written as a dynamic programming problem. Denote the value function of the agent at age $j$ by $V_{j}$ and state vector $x=\left(x_{j}^{2}, e_{j}\right)$.The decision problem of an agent without self-control problems is represented by the following form:

$$
V_{j}(x)=\max _{c_{j}, l_{j}}\left\{u\left(c_{j}, 1-l_{j}\right)+\beta s_{j+1} E V_{j+1}\left(x^{\prime}\right)\right\}
$$

subject to equations 8 and 9 . Note that $x^{\prime}$ denotes the next period's state vector.

The decision problem of an agent with self-control problems can be written as

$$
V_{j}(x)=\max _{c_{j}, l_{j}}\left\{u\left(c_{j}, 1-l_{j}\right)+v\left(c_{j}\right)+\beta s_{j+1} E V_{j+1}\left(x^{\prime}\right)\right\}-\max _{\check{c}_{j}} v\left(\check{c}_{j}\right)
$$

The agent's budget constraint for temptation function reads as follows:

$$
\left\{\begin{array}{c}
\check{c}_{j}+(1+g) \frac{x_{j+1}^{2}}{r} \leq(1+r) \frac{x_{j}^{2}}{r}+y_{j}-T_{j}\left(x_{j}^{1}, x_{j}^{2}, y_{j}\right) \text { when } j<J, \\
\check{c}_{J}=(1+r) \frac{x_{j}^{2}}{r}-T_{j}\left(x_{j}^{1}, x_{j}^{2}, y_{j}\right) \text { when } j=J .
\end{array}\right\}
$$

subject to the equations 8,12 , and 9 . 


\subsection{Equilibrium}

Our equilibrium definition follows Auerbach \& Kotlikoff (1987), Imrohoroglu et al. (2003), and Huggett \& Ventura (1999). We suppose that the pension system is self-financing and the government runs a balanced budget. The pension programs' tax rate, $\tau_{s}$ and the consumption tax rate, $\tau_{c}$ are endogenously determined in order to satisfy the balanced budget conditions.

Given a time-invariant government tax-transfer function $T_{j}\left(x_{j}^{1}, x_{j}^{2}, y_{j}\right)$ and relative prices of labor and capital $\{w, r\}$, a stationary equilibrium is defined as a set of value functions $\left\{V_{j}(x)\right\}_{j=1}^{J}$, individuals' decision rules $\left\{c_{j}(.), x_{j}^{2}(.), l_{j}(.)\right\}_{j=1}^{J,}$, pension program tax rate $\tau_{s}$ and consumption tax rate $\tau_{c}$, and age dependent distributions of individuals $\Lambda_{j}(x)$ that must satisfy the following conditions:

1. Given fiscal policy and prices, individuals' decision rules $\left\{c_{j}(.), \check{c}_{j}(.), x_{j}^{2}(.), l_{j}(.)\right\}_{j=1}^{J,}$ solve

(a) individuals' decision problem 10 subject to constraints 8 and 9 when they have standard preferences.

(b) individuals' decision problem 11 subject to constraints 8,9 , and 12. 9 .

2. The age dependent and time-invariant measure of individuals is computed as follows:

$\Lambda_{j+1}(x)=\sum_{e} \Pi\left(e_{j+1}, e_{j}\right) \int_{X} d \Lambda_{j}$, where $\Pi\left(e_{j+1}, e_{j}\right)$ is the transition matrix for the shocks. $\Lambda_{1}(x)$ is given.

3. Aggregate capital stock, labor supply, and consumption are derived from individuals' behaviors:

$$
\begin{aligned}
K & =\sum_{j=1}^{J} \mu_{j} \int_{X} x_{j}^{2}(x) d \Lambda_{j}, \\
L & =\sum_{j=1}^{j^{*}-1} \mu_{j} \int_{X} l_{j}(x) d \Lambda_{j}, \\
C & =\sum_{j=1}^{J} \mu_{j} \int_{X} c_{j}(x) d \Lambda_{j} .
\end{aligned}
$$

4. Age pension programs are self-financing:

$$
\begin{gathered}
\sum_{j=j^{*}}^{J} \mu_{j} \int_{X} b_{j}\left(x^{1}\right) d \Lambda_{j}=\tau_{s} \sum_{j=1}^{j^{*}-1} \mu_{j} \int_{X} \min \left\{y_{j}(x), y_{\max }\right\} d \Lambda_{j} . \\
\sum_{j=j^{*}}^{J} \mu_{j} \int_{X} b_{j}^{*}\left(x_{j}^{2}\right) d \Lambda_{j}=\tau_{s} \sum_{j=1}^{j^{*}-1} \mu_{j} \int_{X} y_{j}(x) d \Lambda_{j} .
\end{gathered}
$$

5. The sum of accidental bequests satisfies the following equation:

$$
\eta=\sum_{j=1}^{J} \mu_{j} \int_{X}\left(1-s_{j+1}\right) x_{j}^{2}(x) d \Lambda_{j}
$$

6. The government's income tax revenue is given by: 


$$
T_{i}=\sum_{j=1}^{J} \mu_{j} \int_{X} T_{j}^{i n c}(x) d \Lambda_{j}
$$

7. The government runs a balanced budget:

$$
G=T_{i}+\tau_{c} C+\eta
$$

8. The goods market clears:

$$
C+(1+g)(1+n) K+G=Y+(1-\delta) K
$$

\section{Calibration}

This section defines the parameter values of our model. The values of the calibrated parameters for the benchmark economy are presented in Table 1. Since our benchmark model mimics that of Huggett \& Parra (2010), we mainly set model parameters equal to those of Hugget and Parra. In their parameter value setting, Huggett \& Parra (2010) use the values estimated by Kaplan (2012). Estimated values of the model parameters account for the cross-sectional, variance-covariance patterns of hours, consumption, and wages at different ages over the lifecycle.

Demographics Each model period corresponds to a year. Individuals are born at a real age of 25 (model age of 1 ), retire at a real age of 65 (model age of 41) and they can live up to a maximum real life age of 80 (model age of 56). The population growth rate is assumed to be equal to the long-term average growth rate of the US's population i.e. $n=1.1 \%$. The sequence of conditional survival probabilities in the model, $s_{j}$ is set equal to the sequence of conditional survival probabilities taken from Conesa et al. (2009).

Labor Productivity Process An agent's labor productivity is $\omega\left(e_{j}, j\right)=\zeta_{j} \exp \left(e_{j}^{1}+\right.$ $\left.e_{j}^{2}+e_{j}^{3}\right)$. Labor productivity has two major components: a deterministic component $\zeta_{j}$ and an idiosyncratic shock component $e_{j}=\left(e_{j}^{1}+e_{j}^{2}+e_{j}^{3}\right)$. The idiosyncratic shock component captures the differences in the permanent $\left(e_{j}^{1}\right)$, persistent $\left(e_{j}^{2}\right)$, and temporary $\left(e_{j}^{3}\right)$ sources of productivity. The permanent component stays fixed over the agent's life-cycle and is normally distributed by $N\left(-\sigma_{1}^{2} / 2, \sigma_{1}^{2}\right)$. The persisitent component follows the following autoregressive process: $e_{j}^{2}=\rho e_{j-1}^{2}+\varphi_{j}, \varphi_{j} \sim N\left(0, \sigma_{2}^{2}\right)$. The temporary component $e_{j}^{3}$ is distibuted by $N\left(-\sigma_{3}^{2} / 2, \sigma_{3}^{2}\right)$. An agent's wage at age $j$ is determined by a fixed wage rate $w$ per efficiency unit of labor and by labor productivity $\omega\left(e_{j}, j\right)$. We set the persistent shock to zero for each agent at model age of 1 . The deterministic component is set in a way that wages approximately double over the life cycle. Each productiivy process is approximated with a discrete number of shocks. ${ }^{6}$

\footnotetext{
${ }^{6}$ The approximation process follows Tauchen (1986). For details see Huggett \& Parra (2010).
} 
Preferences We use an additively seperable period utility function: Individuals have time-separable preferences over consumption and leisure:

$$
u(c, 1-l)=\frac{c^{(1-\nu)}}{(1-v)}+\kappa \frac{(1-l)^{(1-\gamma)}}{(1-\gamma)} .
$$

The period temptation function is given as $\lambda u(c, 1-l)$, where $\lambda$ is a temptation parameter. Following the earlier literature on temptation we assume individuals are tempted to consume all their wealth in a given period i..e. $\check{c}_{j}=(1+r) \frac{x_{j}^{2}}{r}+\hat{y}_{j}-T_{j}\left(x_{j}^{1}, x_{j}^{2}, y_{j}\right)$, where $\hat{y}_{j}$ is the labor income when temptation consumption is chosen. Following Huggett \& Parra (2010), we set the period utility function parameters equal to Kaplan (2012)'s estimates. These estimates are compatible with the values estimated in the literature by using micro-level consumption and labor data. In particular, we set the coefficient of risk aversion parameter $(v)$ equal to 1.66 and the coefficient that governs the Frisch elasticity of labor $(\gamma)$ equal to $5.55 .^{7}$ Finally, we set $\kappa=0.13$, which is the mean value estimated by Kaplan (2012). We follow DeJong \& Ripoll (2007) and Kumru \& Thanopoulos (2011) in choosing the values of the temptation strength parameter $\lambda$. We set the value of the time-discount factor $\beta$ in a way that it generates the target capital-output ratio.

Government Policy The parameter values of the benchmark model's tax-transfer system are chosen in a way that they can mimic the features of the US social security and income tax system. In particular, we set the social secuirty tax rate $\tau$ to $10.6 \%$. The social security benefit function and income tax function follow the US tax-transfer system closely as we expressed in more detail earlier. We set the minimum guaranteed value of means-tested pension income, $b^{\text {max }}$ to $5 \%$ of output per capita in the model. This benefit is reduced by a taper rate applied to any private income. We vary the taper rates at $10 \%$ increments between $0 \%$ and $100 \%$.We set government expenditure $G$ to $22 \%$ of GDP.

\footnotetext{
${ }^{7}$ Note that the Frisch elasticity of labor supply is equal to 0.27 when $\gamma=5.55$ and $l=0.4$.
} 


\begin{tabular}{|c|c|c|}
\hline Parameter & Value & Target \\
\hline \multicolumn{3}{|l|}{ Demographics } \\
\hline Maximum possible life span $J$ & 56 (real age of 80 ) & Assumed certain death \\
\hline Obligatory retirement age $j^{*}$ & 41 (real age of 65 ) & Assumed compulsory retirement \\
\hline Growth rate of population $n$ & $1.1 \%$ & Data \\
\hline Conditional survival probabilities $\left\{s_{j}\right\}_{j=1}^{J}$ & Conesa et al. (2009) & Data \\
\hline \multicolumn{3}{|l|}{ Endowments } \\
\hline $\begin{array}{l}\text { Age efficiency profile }\left\{\bar{e}_{j}\right\}_{j=1}^{j^{*}-1} \\
\left(\sigma_{1}^{2}, \sigma_{2}^{2}, \sigma_{3}^{2}, \rho\right)\end{array}$ & $\begin{array}{l}\text { Kaplan }(2007) \\
(.056, .019, .072, .946)\end{array}$ & $\begin{array}{l}\text { Data } \\
\text { Data }\end{array}$ \\
\hline \multicolumn{3}{|l|}{ Preferences } \\
\hline Annual discount factor of utility $\beta$ & 0.995 & $\mathrm{~K} / \mathrm{Y}=2.7$ \\
\hline$v$ & 1.66 & $\mathrm{IES}=0.5$ \\
\hline$\gamma$ & 5.55 & Frisch Elasticity $=0.27$ \\
\hline$\kappa$ & 0.13 & Data \\
\hline Temptation parameter $\lambda$ & DeJong (2007) & Data \\
\hline \multicolumn{3}{|l|}{ Government } \\
\hline Social security tax rate $\tau_{s}$ & $\% 10.6$ & Hugget and Parra (2009) \\
\hline Social security benefit function & Huggett and Parra (2009) & Data \\
\hline Minimum guaranteed pension income $b^{\max }$ & $5 \%$ of output per capita & \\
\hline Taper rate $\phi$ & Various rates & \\
\hline Consumption tax rate $\tau_{c}$ & $5 \%$ & Conesa et al. (2009) \\
\hline Income tax & Huggett and Parra (2009) & Data \\
\hline
\end{tabular}

Table 1: Parameter Values of The Benchmark Calibration

\section{Results}

We have two economies that are identical except individuals' preference specifications. In the first economy, all individuals have standard preferences while in the second economy individuals have self-control preferences. Our aim here is to compare the aggregate and welfare consequences of the replacement of the current PAYG social security system with a resource tested old age pension program. In our experiments, we first keep the expected present value cost (EPVC) of various programs fixed.

As a result, for each taper rate, we need to increase the amount of the maximum benefits to keep the EPVC constant across programs. Keeping the cost of the programs constant allows us to pin down the welfare effects of the various taper rates only. The earlier studies (see for example Sefton et al. (2008)) that analyze the welfare effects of resource testing basically vary taper rates without adjusting the maximum amount of pensions. This, in turn results in various programs that differ in terms of costs and make an isolated comparison harder. From Table 2 we see that replacing the current progressive PAYG system by a means tested pension program of equivalent cost, results in welfare loss. Table 2 also reveals that, among the compared taper rates, the $80 \%$ taper rate resource testing program is the best. Compared to the $100 \%$ taper rate, the $80 \%$ allows a higher fraction of the population (mainly coming from relatively higher incomes) to "pass" the means-testing criterion and thus enjoy retirement benefits. At the same 


\begin{tabular}{lllll}
\hline \hline Taper Rate & Max Pension Benefit & EPVC & L & EU \\
\hline PAYG & & -0.95 & 0.3921 & 100 \\
0 & 0.041 & -0.95 & 0.3715 & 99.0757 \\
0.2 & 0.074 & -0.95 & 0.3732 & 99.1344 \\
0.4 & 0.100 & -0.95 & 0.3739 & 99.1551 \\
0.6 & 0.121 & -0.95 & 0.3745 & 99.1554 \\
0.8 & 0.138 & -0.95 & 0.3749 & 99.1604 \\
1 & 0.152 & -0.95 & 0.3751 & 99.1469 \\
\hline \hline
\end{tabular}

Table 2: Standard Preferences - Fixed Cost Pension System

\begin{tabular}{lllll}
\hline \hline Taper Rate & Max Pension Benefit & EPVC & L & EU \\
\hline PAYG & & -0.95 & 0.3921 & 100 \\
0 & 0.041 & -0.95 & 0.3715 & 99.0757 \\
0.2 & 0.041 & -0.48 & 0.3675 & 101.3546 \\
0.4 & 0.041 & -0.29 & 0.3655 & 102.2472 \\
0.6 & 0.041 & -0.22 & 0.3656 & 102.5866 \\
0.8 & 0.041 & -0.18 & 0.3642 & 102.7968 \\
1.0 & 0.041 & -0.14 & 0.3639 & 102.9437 \\
\hline \hline
\end{tabular}

Table 3: Standard Preferences - Variable Cost Pension System

time, the fact that the taper rate is not very low, allows for the maximum benefit (to be given mainly to lower incomes) to remain high, in order to keep EPVC constant. So, overall welfare is maximized, because there is an improvement on both extremes of the income distribution that pass the means testing criterion. This result is interesting in the sense that the replacement of a progressive earnings-related PAYG program by a resource testing program ends up reducing welfare for all taper rates considered.

In our second experiment (Table 3), we keep benefits constant and vary taper rates. Hence, the EPVC of the resource testing program varies with taper rates i.e. the higher the taper rate is, the lower the EPVC. When we keep benefits fixed, replacing the PAYG program by a means-tested program increases welfare. Not surprisingly, the higher the taper rate, the larger the welfare gain is, since an increased fraction of the population ends up passing the criterion and enjoys retirement benefits. Cross-comparison of this experiment with the earlier one reveals that the welfare gain coming from the replacement of a PAYG system by a meanstested program hinges on the lower EPVC. When we control the cost, there is no welfare gain through means-test replacement, yet substantial welfare gain occurs when PAYG is replaced by means-tested pension programs of increasingly higher taper rates.

In Table 4, we present the results of our experiments assuming individuals suffer from selfcontrol problems. Earlier studies firmly established that the negative welfare implications of a PAYG program are mitigated when individuals have self-control preferences. Yet, we do not know whether self-control problems and resource tested pension programs interact in a similar 


\begin{tabular}{lllll}
\hline \hline Taper Rate & Max Pension Benefit & EPVC & L & EU \\
\hline PAYG & & -0.95 & 0.3937 & 100 \\
0.0 & 0.041 & -0.95 & 0.3799 & 99.6837 \\
0.2 & 0.070 & -0.95 & 0.3812 & 99.6735 \\
0.4 & 0.095 & -0.95 & 0.3821 & 99.6475 \\
0.6 & 0.114 & -0.95 & 0.3825 & 99.6202 \\
0.8 & 0.129 & -0.95 & 0.3827 & 99.5932 \\
1.0 & 0.141 & -0.95 & 0.3830 & 99.5379 \\
\hline \hline
\end{tabular}

Table 4: Self-control Preferences - Fixed Cost Pension System

\begin{tabular}{lllll}
\hline \hline Taper Rate & Max Pension Benefit & EPVC & L & EU \\
\hline PAYG & & -0.95 & 0.3937 & 100 \\
0.0 & 0.041 & -0.95 & 0.3799 & 99.6837 \\
0.2 & 0.041 & -0.53 & 0.3762 & 101.7924 \\
0.4 & 0.041 & -0.33 & 0.3741 & 102.7502 \\
0.6 & 0.041 & -0.25 & 0.3732 & 103.1369 \\
0.8 & 0.041 & -0.20 & 0.3730 & 103.3675 \\
1.0 & 0.041 & -0.17 & 0.3727 & 103.5093 \\
\hline \hline
\end{tabular}

Table 5: Self-control Preferences - Variable Cost Pension System

fashion. Table 4 tells us that, when the EPVC of the programs is fixed, the welfare consequences of replacing the PAYG with a resource testing program is similar between an economy populated by standard agents and one populated by self-control agents, i.e., the PAYG dominates any resource testing problem. Yet, there are two main differences between the two economies. Welfare decreases relatively less in the self-control economy and among resource testing pension programs, the program with $0 \%$ taper rate generates the highest welfare. In order to secure "universal access" to the minimum pension benefit (no actual means testing) while at the same time keep EPVC constant, the maximum pension benefit has to fall considerably. This, in turn, spares self-control agents from the consumption opportunities they would have if they had higher maximum pension benefits, hence, the lower the taper rate, the better for the higher income self control individuals. In this environment it seems that the welfare implications of various taper rates are not much affected by the existence of self-control problems.

When we fix pension benefits (Table 5), on the other hand, we see that higher taper rates generate much higher welfare gain when individuals have self-control problems. This could be again due to the fact that self-control agents are deprived consumption opportunities.

\section{Conclusion}

Means testing has come to add yet another important dimension in the academic and policy debate regarding the monetary burden that the mere presence and administration of a social 
security system entails for the society, and the associated budget implications that the provision of old age, disability, unemployment and health insurance effectively has. On the one hand, population aging has raised challenges and concerns to policy makers about the adequacy of the existing insurance programs to deal with the consumption needs of a growing number of elderly dependents. Although age pension programs vary in terms of their benefit, financing and coverage structures, they all provide longevity insurance and can be welfare improving when private annuities markets are missing or when individuals do not save enough for retirement because of myopia. On the other hand, amidst the economic crisis, markets are concerned about long-term fiscal sustainability and the ability of policy makers to address these challenges, especially in debt laden countries.

In this paper, we explored quantitatively the welfare consequences of introducing means testing of pensions as an alternative to an earnings dependent and progressive "unfunded" (PayAs-You-Go) program when agents have self-control preferences. To this end, we employed a partial equilibrium OLG model with labor-leisure choice, uninsurable individual income shocks, borrowing constraints and missing annuity markets, and calibrated our economy to that of the US.

Our analysis was executed in two stages involving two economies that only differ in agents' preference specifications, but are identical in all other aspects. Our ultimate goal has been to assess, from a welfare standpoint, the scope of the introduction of means-testing to an earningsdependent and progressive "unfunded" (Pay-As-You-Go) scheme, without altering the expected present value cost (EPVC) of the latter.

Our paper's contribution to the literature is two-fold: first, it enhances the scope of studies on means-testing by taking self-control issues into consideration. This allows us to analyze the possible interaction between means-testing and self-control issues, and to explore the possibility to identify separately the disincentives to savings that are due to either of those. Second, in contrast to earlier studies on means-testing, our paper compares means-tested programs in two different settings. In the first setting, we keep the expected present value cost of the all programs, including the PAYG program, constant. This allows us to isolate the implications of the phase-out rate. Later, we also look at the implications of the means-testing, varying the taper rate while keeping the minimum guaranteed benefit fixed, i.e., varying the EPVC.

Our results can prove useful from both a theoretical and a policy making perspective. On the former front, disentangling the effects that self control on the one hand, and the taper rate on the other, have on savings behavior, allows for a more realistic assessment of means-testing in terms of welfare in light of recent findings in the economics literature that highlight the importance of preferences. On the latter front, policy makers should be cautious with policy recommendations based on fine-tuning of a tool such as the taper rate, as this may function in a complementary way with unobserved heterogeneity in agents' preferences (here, self-control issues) and compromise severely the effectiveness of the tool.

Our results show that individuals' self-control problems would have a role in determining the welfare ranking of the programs. When the cost of the system fixed, lower taper rates do 
not generate additional tax distortions. When individuals have standard preferences, $80 \%$ taper rate generates the highest welfare among the means-tested programs. This is because $80 \%$ taper rates improves the distribution of income and hence, generates higher welfare. Interestingly, when individuals have self-control preferences, $0 \%$ taper rate generates the highest welfare among means-tested programs. When individuals have self-control preferences, they would like to avoid high temptation. Higher taper rates enlarge the choice sets of certain individuals and increase their self-control costs. On other hand, $0 \%$ taper rate provides a lower amount of benefits to all individuals without increasing certain individuals' self-control costs. In other

words, when individuals have self-control preferences, $0 \%$ taper rate's self-control cost reducing benefit exceeds higher taper rates' redistributional benefits.

When the cost of the program is varied, lower taper rates come up with huge tax distortions and hence, in both cases, means-tested programs with $100 \%$ taper rates maximizes the welfare. In this case, it is important to note that, all means-tested programs generate higher welfare benefits than the PAYG pension program. When individuals have self-control references, higher taper rates generate larger welfare gain. Since the cost of the system varies, even individuals with self-control preferences prefer the system with low tax distortions.

\section{References}

Angeletos, George-Marios, Laibson, David, Repetto, Andrea, Tobacman, Jeremy, \& Weinberg, Stephen. 2001. The Hyperbolic Consumption Model: Calibration, Simulation, and Empirical Evaluation. The Journal of Economic Perspectives, 15, 47-68.

Auerbach, A. J., \& Kotlikoff, L. J. 1987. Dynamic Fiscal Policy. New York, NY, USA: Cambridge University Press.

Conesa, J. C., Kitao, S., \& Krueger, D. 2009. Taxing capital? Not a bad idea after all! American Economic Review, 99, 25-48.

DeJong, D. N., \& Ripoll, M. 2007. Do self-control preferences help explain the puzzling behavior of asset prices? Journal of Monetary Economics, 54, 1035-1050.

Diamond, P. A. 1965. National debt in a neoclassical growth model. American Economic Review, 55, 1126-1150.

Fehr, Hans, Habermann, Christian, \& Kindermann, Fabian. 2008. Social Security with Rational and Hyperbolic Consumers. Review of Economic Dynamics, 11(4), 884-903.

Feldstein, Martin. 1985. The Optimal Level of Social Security Benefits. The Quarterly Journal of Economics, 100, 303-320.

Golosov, Mikhail, \& Tsyvinski, Aleh. 2006. Designing Optimal Disability Insurance: A Case for Asset Testing. Journal of Political Economy, 114, 257-279. 
Gul, F., \& Pesendorfer, W. 2004. Self control and theory of consumption. Econometrica, 72, 119-158.

Huggett, M., \& Parra, J. C. 2010. How Well Does the U.S. Social Insurance System Provide Social Insurance? Journal of Poliitcal Economy, 118, 76-112.

Huggett, M., \& Ventura, G. 1999. On the distributional effects of social security reform. Review of Economic Dynamics, 2, 498-531.

Imrohoroglu, A., Imrohoroglu, S., \& Joines, D. H. 1995. A life cycle analysis of social security. Economic Theory, 6, 83-114.

Imrohoroglu, A., Imrohoroglu, S., \& Joines, D. H. 2003. Time inconsistent preferences and social security. Quarterly Journal of Economics, 118, 745-784.

Kaplan, Greg. 2012. Inequality and the life cycle. Quantitative Economics, 3, 471-525.

Kitao, Sagiri. 2014. Sustainable Social Security: Four Options. Review of Economic Dynamics.

Kumru, C. S., \& Thanopoulos, A. 2011. Social security reform with self-control preferences. Journal of Public Economics, 95, 886-899.

Kumru, C. S., \& Thanopoulos, A. C. 2008. Social security and self control preferences. Journal of Economic Dynamics and Control, 32, 757-778.

Kumru, Cagri S, \& Piggott, John. 2009. Should Public Retirement Provision Be Means-tested? Australian School of Business Research Paper No. 2009 AIPAR 01.

Phelps, E. S., \& Pollak, R. A. 1968. On second-best national savings and game-equilibrium growth. Review of Economic Studies, 35, 185-199.

Sefton, J., van de Ven, J., \& Weale, M. 2008. Means testing retirement benefits: Fostering Equity or Discouraging Savings? Economic Journal, 118, 556-590.

Sefton, James, \& van de Ven, Justin. 2009. Optimal Design of Means Tested Retirement Benefits. Economic Journal, 119, 461-481.

Storesletten, K., Telmer, C. I., \& Yaron, A. 1999. The risk sharing implications of alternative social security arrangements. Carnegie-Rochester Conference Series on Public Policy, 50, 213-259.

Strotz, R. H. 1956. Myopia and inconsistency in dynamic utility maximization. Review of Economic Studies, 23, 165-180. 